\title{
Assessment of partograph utilization and associated factors among obstetric care givers at public health institutions in central zone, Tigray, Ethiopia
}

\author{
Tesfay Hailu*, Kidane Nigus, Gebreamlak Gidey, Birhane Hailu and Yohannes Moges
}

\begin{abstract}
Objectives: Partograph is one of the best effective obstetric tools used to monitoring labor and prevent prolonged or obstructed labor which accounts for about 22\% of maternal deaths in Ethiopia. This study was aimed to assess partograph utilization and associated factors among obstetric care givers. Facility based cross sectional study was used in the randomly selected health facilities. Total 220 obstetric care givers were selected using simple random sampling technique. Data were entered and analyzed using SPSS version 22.0. Bivariate and multivariate logistic regression analysis was used to identify the associations of each explanatory variable with the outcome variable. Finally, odds ratio with its $95 \%$ confidence interval and p-value of 0.05 was used to identify significant variables.

Result: Out of 198 obstetric care providers, $73.3 \%$ used partograph to monitor progress of labor. Those who were diploma holders ( $\mathrm{AOR}=3.8, \mathrm{Cl}=2.2-6.2$ ), receiving basic emergency obstetrics and new born care training $(\mathrm{AOR}=5.6, \mathrm{Cl} 1.1-28.5)$, age between 20 and 29 years-old $(\mathrm{AOR}=0.1, \mathrm{Cl}=0.01-0.50)$, and male health care providers ( $A O R=0.37, C l=0.44-0.95)$ were factors significantly associated with partograph utilization. Partograph utilization in this study was below the WHO recommendation. Especial emphasizes and interventions should be given to increase partograph utilization.
\end{abstract}

Keywords: Partograph, Utilization, Obstetric care givers, Ethiopia

\section{Introduction}

The tragedy of maternal mortality in Ethiopia is that despite the recognition of maternal mortality as a major public health issue, maternal mortality figures continue to rise, in spite of the apparent commitment by stakeholders. The majority of the deaths and complications could be prevented by cost-effective and affordable health interventions like the partograph [1].

The partograph is an effective tool for monitoring labor, and when used effectively, it prevents obstructed labor, which accounts for about $8 \%$ of maternal deaths worldwide. Thus it serves as an 'early warning system'

\footnotetext{
${ }^{*}$ Correspondence: tesfayhailu20@yahoo.com

Department of Midwifery, College of Health Science and Referral Hospital,
}

Aksum University, Axum, Ethiopia and assists in early decision on transfer, intervention decisions in hospitals and ongoing evaluation of the effect of interventions. Partograph has been promoted by the World Health Organization as the "gold" standard for assessing progress in labor in most low resource countries like Ethiopia $[1,2]$.

Approximately 300,000 maternal deaths occurred globally in 2013, of which $98 \%$ occurred in the developing countries. On the average 230 women die per every 100,000 live births every year in developing countries [3].

The burden of maternal death is not uniformly distributed throughout the world. Obstetric risk is by far the highest in sub-Saharan Africa. In 2015, the MMR for sub-Saharan Africa was estimated to be nearly 546 per 100,000 live birth, three times higher than that of South Asia (182 per 100,000), eight times higher than in Latin 
America and the Caribbean (68 per 100,000), and more than 30 times higher than in industrialized countries (16 per 100,000) [4-6].

In Ethiopia, maternal death is still high. It is estimated 412 per 100,000 live births. However, Eighty-five percent of deaths can be prevented with cost effective interventions like partograph during labor and delivery [7].

Even thought, prolonged labor is the most common cause of death among mothers and new-born in a developing country that in turn, leads the woman to face serious complication related to obstructed labor, dehydration, exhaustion, or rupture of the uterus and infection. Obstructed labor is also other most common cause of maternal death in developing world [8].

World Health Organization recommends the universal utilization of the partograph during labor and routine use of partograph is helpful to make better decisions for the diagnosis and management of prolonged and obstructed labor [9]. Studies showed that, prevention of prolonged and obstructed labor by using partograph during labor is a key intervention in the reduction of maternal and perinatal morbidity and mortality [10].

Evidences from developing country including Ethiopia demonstrated that, the utilization of partograph is poor despite preparing the tool that is simple and inexpensive for intra partum monitoring of labor $[8,10]$.

In Ethiopia, since the major sources of maternal and neonatal morbidity and mortality are related to poor labor and delivery care [11]. Even though, partograph is a tool which is helpful to manage obstructed labor and prevent prolonged labor with its complications, still the level of utilizations and factors affecting to use among obstetric care providers were not yet studied in the study area. Therefore, in this study, we aimed to determine the level of partograph use and identify the factors associated with its use among obstetric caregivers in central zone of Tigray, northern Ethiopia.

\section{Main text}

\section{Study area and period}

This study was conducted in randomly selected public health institutions of central zone of Tigray which is located at $1028 \mathrm{~km}$ away from the capital city of Ethiopia, Addis Ababa and $245 \mathrm{~km}$ from Mekelle, which is the administrative city of the Region. The study was conducted from October 2016 to April 2017.

\section{Study design}

Institutional based cross-sectional survey was conducted.

\section{Sample size}

The sample size was estimated using single proportion formula by assuming 5\% marginal error and 95\% confidence interval $(\sigma=0.05)$ and study conducted in Addis Ababa city in which the proportion of utilization of partograph among obstetric care givers were 57.3\% [8]. By adding $5 \%$ for non-respondents the final sample size was taken as 220 .

\section{Sampling procedure}

All health institutions found in central zone of Tigray were included and 37 health institutions were selected using simple random sampling technique. The total sample size of the study was distributed over each of the institute proportional to their size and the required number of study subjects was selected randomly from each selected public health institutions.

\section{Data collection instrument and techniques}

A structured questionnaire which was developed from different literatures was used. It was prepared in English and translated to Tigrigna (local language) and translated back to English to check consistency. Ten data collectors and two supervisors were hired during the data collection period.

\section{Data processing and analysis}

Data was entered, checked, and analyzed using SPSS version 22.0. Descriptive statistics was employed to calculate frequencies, mean and percentage. Bivariable logistic regression analysis was made using OR and $95 \%$ $\mathrm{CI}$ to assess the association of independent variable with the outcome separately. Based on Bivariate analysis variables that showed significant association at $(\mathrm{p}<0.2)$ were entered to multivariable analysis to select Predictor variables of factors affecting partograph utilization. Finally, variables that showed significant association at $(\mathrm{p}<0.05)$ were identified as independent predictors of partograph utilization.

\section{Ethical considerations}

The Ethical approval was obtained from Institutional Review Board of College of Health Sciences, Aksum University. Communications with relevant bodies was made through a formal letter obtained from regional health. The objective and importance of the study was explained to the study participants. Data was collected after full informed written consent was obtained from participants. Confidentiality of the information and privacy is maintained.

\section{Socio-demographic characteristics of study participants} Out of 220 study participants, 198 (90\%) properly completed questionnaires were analyzed. About $65.7 \%$ of obstetric care providers were females. Majority of the study participants, 83 (41.9\%) were in the age group of 
Table 1 Socio-demographic characteristics of obstetric care givers at public health institutions in central zone, Tigray, Ethiopia/2017

\begin{tabular}{|c|c|c|}
\hline Variables, $N=198$ & Frequency & Percentage \\
\hline \multicolumn{3}{|l|}{ Sex } \\
\hline Male & 68 & 34.3 \\
\hline Female & 130 & 65.7 \\
\hline \multicolumn{3}{|l|}{ Age } \\
\hline $20-29$ & 83 & 41.9 \\
\hline $30-39$ & 52 & 26.3 \\
\hline $40-49$ & 53 & 26.8 \\
\hline$\geq 50$ & 10 & 5.1 \\
\hline \multicolumn{3}{|l|}{ Profession } \\
\hline Health officer & 26 & 13.1 \\
\hline Nursing & 33 & 16.7 \\
\hline Midwifery & 139 & 70.2 \\
\hline \multicolumn{3}{|l|}{ Level of education } \\
\hline Diploma & 112 & 56.6 \\
\hline Degree & 71 & 35.9 \\
\hline Others & 15 & 7.6 \\
\hline \multicolumn{3}{|l|}{ Working experience } \\
\hline Less than 2 years & 50 & 25.3 \\
\hline $2-5$ years & 52 & 26.3 \\
\hline 5 years and above & 96 & 48.5 \\
\hline \multicolumn{3}{|c|}{ Current working department } \\
\hline Delivery room & 148 & 74.7 \\
\hline ANC/PNC/FP & 23 & 11.6 \\
\hline Other & 27 & 13.6 \\
\hline \multicolumn{3}{|c|}{ Involved in labor and delivery } \\
\hline Yes & 192 & 97.0 \\
\hline No & 6 & 3.0 \\
\hline \multicolumn{3}{|c|}{ Received training on BEmONC } \\
\hline Yes & 130 & 65.7 \\
\hline No & 68 & 34.3 \\
\hline
\end{tabular}

20-29 years. From all study participants, 112 (56.6\%) of the healthcare providers had a diploma educational status. Regarding their profession, 139 (70.2\%) were midwives followed by nurses 33 (16.7\%). One hundred forty-eight $(74.7 \%)$ of the obstetric care givers were working at delivery ward currently while the rest were working in antennal ward, family planning and postnatal wards. Nearly half, 96 (48.5\%) of obstetric caregivers, had 5 years and above of clinical service and about 130 (65.7\%) of them had trained on Basic Emergency Obstetric and Newborn care training (Table 1).

\section{Level of knowledge towards the use of partograph}

Overall 135 participants (68.2\%) had a satisfactory knowledge of benefit of partograph and recording observation on partograph (Additional file 1: Table S1).
Attitude of the participant towards the use of partograph Most of study participants, 134 (67.7\%), had favorable attitude towards partograph utilization. Almost all the study participants, 197 (99.5\%) agreed that using partograph decreases risks of mother/infant morbidity and mortality (Additional file 1: Table S2).

\section{Practice of participants towards the use of partograph} The majority, $73.3 \%$ (95\% CI 67.7-79.8) of obstetric care providers were utilize partograph to monitor labor. The practice of respondents on frequency of recording observation on the partograph shows: $146(100 \%)$ for cervical dilatation, $144(98.6 \%)$ for fetal heartbeat, 146 (100\%) for color of liquor, $146(100 \%)$ for contraction, $142(97.3 \%)$ for descent, 146 (100\%) for maternal BP, 145 (99.3\%) for maternal pulse, 146 (100\%) for the first dilatation plotted on the alert line, and 139 (95.2\%) for membrane intact or ruptured (Table 2).

Factors associated with partograph utilization by obstetric care providers

According to the multivariable analysis, obstetric care providers holding a diploma were 3.8 times more likely to use the partograph than M.Sc. and above [AOR (95\% CI) 3.8 (2.20-6.20)]. Obstetric caregivers who were received Basic emergency obstetric and new born care training were 5.6 times more likely to use the photograph than those who did not trained [AOR $(95 \% \mathrm{CI})$ 5.6 (1.10-28.50)]. Moreover, caregivers whose age between 20 and 29 years-old were $90 \%$ less likely to use partograph during labor and delivery than those ages $\geq 50$ years-old [AOR $(95 \% \mathrm{CI}) 0.1(0.01-0.50)$ ] Similarly, Male obstetric caregivers were also 63\% times less likely to use the partograph than their counterparts [AOR (95\% CI) 0.37 (0.44-0.95)] (Table 3).

\section{Discussion}

The aim of this study was to identify utilization of partograph and associated factors among obstetric care providers in central zone of Tigray, northern Ethiopia. The prevalence of partograph utilization was found to be $73.3 \%$. This finding is lower than studies conducted in Delta Region of Nigeria (98.8\%) and Calabar, Nigeria $(80.7 \%)[12,13]$. But this study result was higher than the findings from other studies like; Addis Ababa, Ethiopia (57.4\%) [8] and in South West Nigeria (32.3\%) [14].

The possible reason for this variation could be due to the availability of well-designed and coordinated programs like; the strength of mentorship, supportive supervision. Other reasons might be time of the study, competency level and background characteristics of the study participants. 
Table 2 Practice of partograph among obstetric care givers at public health institutions central zone, Tigray, Ethiopia/2017

\begin{tabular}{|c|c|c|}
\hline Variable, $\mathrm{N}=198$ & Frequency & Percent \\
\hline \multicolumn{3}{|c|}{ Health institution have labor management protocol } \\
\hline Yes & 183 & 92.4 \\
\hline No & 15 & 7.6 \\
\hline \multicolumn{3}{|c|}{ Partograph attached to the chart and properly filled } \\
\hline Yes & 146 & 73.7 \\
\hline No & 52 & 26.3 \\
\hline \multicolumn{3}{|c|}{ Membrane intact/ruptured recorded } \\
\hline Yes & 139 & 95.2 \\
\hline No & 7 & 4.8 \\
\hline \multicolumn{3}{|l|}{ FHB plotted half hourly } \\
\hline Yes & 144 & 98.6 \\
\hline No & 2 & 1.4 \\
\hline \multicolumn{3}{|l|}{ Color of liquor recorded } \\
\hline Yes & 146 & 100 \\
\hline No & 0 & 0 \\
\hline \multicolumn{3}{|c|}{ First dilatation plotted on the alert line } \\
\hline Yes & 146 & 100 \\
\hline No & 0 & 0 \\
\hline \multicolumn{3}{|l|}{ Cervical dilatation plotted $4 \mathrm{~h}$ apart } \\
\hline Yes & 146 & 100 \\
\hline No & 0 & 0 \\
\hline \multicolumn{3}{|l|}{ Descent plotted four hourly } \\
\hline Yes & 142 & 97.3 \\
\hline No & 4 & 2.7 \\
\hline \multicolumn{3}{|c|}{ Uterine contraction plotted half hourly } \\
\hline Yes & 146 & 100 \\
\hline No & 0 & 0 \\
\hline \multicolumn{3}{|c|}{ Maternal BP recorded on admission } \\
\hline Yes & 146 & 100 \\
\hline No & 0 & 0 \\
\hline \multicolumn{3}{|c|}{ Maternal pulse monitored every $30 \mathrm{~min}$} \\
\hline Yes & 145 & 99.3 \\
\hline No & 1 & 0.7 \\
\hline \multicolumn{3}{|l|}{ Mother delivered in health center } \\
\hline Yes & 135 & 92.5 \\
\hline No & 11 & 7.5 \\
\hline \multicolumn{3}{|c|}{ According the partograph the women delivered } \\
\hline On or left of alert line & 104 & 77.0 \\
\hline Between alert and action line & 21 & 15.6 \\
\hline At or beyond action line & 10 & 7.4 \\
\hline
\end{tabular}

This study revealed that obstetric care givers, whose age range between 20 and 29 years-old were less likely to use partograph than their counterparts. This finding is in contrast with study done in Addis-Ababa, Sidama and Assela in which age of the participants did not show a significant association with partograph utilization $[8,15,16]$. The possible reason for this difference could be due to difference in age categorization, sample size and time of study. On the other hand it can be due to non-experienced fresh graduates may have gaps on their level of competency during the pre-service training on how to plot partograph.

Findings of the current study also indicated that significant association between sex and partograph utilization. Being female's obstetric care givers towards partograph utilization were higher than among male. This might be due to females are closer to obstetric information as they have a tendency to become midwives which makes more likely to have good knowledge of components of the partograph to utilize it than males. This finding may be entry point for health institutions and other stake holders to work on how to increase male involvement in partograph utilization. This finding is consistent with a previous study done in Assela, Ethiopia [15].

The utilization of the partograph was significantly higher among obstetric care givers holding a diploma compared to Masters of Science and above. This is consistent with the study conducted in East Gojjam, Ethiopia. It might be due to the fact that diploma holders are assigned in the remote non equipped health centers comparing to Masters of Science and above holders and might have a better chance to get refreshment training to use the partograph in identifying abnormal labor progress early, as well as arranging for the timely referral to higher health facilities [17].

Training on basic emergency obstetrics and newborn care had a significant association with partograph utilization. Obstetric care providers who received training on basic emergency obstetrics and newborn care were about 5.6 times more likely to utilize partograph than their counterpart. This finding is consistent with a previous study done in Shoa, Ethiopia. This observation could be explained by the fact that, obstetric care providers who received training had better exposure to practice about partograph and in basic emergency obstetric and new born care training, partograph is included as an indicator [9].

\section{Conclusion}

Although world health organization recommends utilizations of partograph for all laboring women greater than one-fourth of obstetric care givers in this study hadn't used partograph. Age, sex, Level of education and presence of training were significantly associated with utilization of partograph.

\section{Recommendation}

Providing obstetric care training for obstetric care givers about partograph in particular, would improve partograph utilization. Furthermore, regular supportive supervision will be important to improve obstetric care in general and proper utilization of the partograph. 
Table 3 Factors associated with partograph utilization of obstetric care giver in public Health institution in central zone, Tigray, Ethiopia/2017

\begin{tabular}{|c|c|c|c|c|}
\hline \multirow[t]{2}{*}{ Variables } & \multicolumn{2}{|c|}{ Utilization of partograph } & \multirow[t]{2}{*}{ COR $(95 \% \mathrm{Cl})$} & \multirow[t]{2}{*}{ AOR $(95 \% \mathrm{Cl})$} \\
\hline & Yes & No & & \\
\hline \multicolumn{5}{|l|}{ Age } \\
\hline $20-29$ & $64(77.1 \%)$ & 19 (22.9\%) & $0.3(0.07-1.14)^{*}$ & $0.10(0.01-0.50)^{*}$ \\
\hline $30-39$ & $34(65.4 \%)$ & $18(34.6 \%)$ & $0.53(0.14-2.07)$ & $0.22(0.03-1.55)$ \\
\hline $40-49$ & $43(81.1 \%)$ & $10(18.9 \%)$ & $0.23(0.10-0.69)$ & $0.10(0.01-0.41)$ \\
\hline$\geq 50$ & $5(50 \%)$ & $5(50 \%)$ & 1 & 1 \\
\hline \multicolumn{5}{|l|}{ Sex } \\
\hline Male & $57(83.8 \%)$ & $11(16.2 \%)$ & $0.42(0.20-0.90)^{*}$ & $0.37(0.44-0.95)^{*}$ \\
\hline Female & $89(68.5 \%)$ & $41(31.5 \%)$ & 1 & 1 \\
\hline \multicolumn{5}{|l|}{ Profession } \\
\hline Health officer & 17 (65.4\%) & $9(34.6 \%)$ & $1.3(0.52-3.07)$ & $3.9(0.61-4.70)$ \\
\hline Nursing & 31 (93.9\%) & $2(6.1 \%)$ & $0.15(0.04-0.67)$ & $0.23(0.30-1.80)$ \\
\hline Midwifery & $98(70.5 \%)$ & $41(29.5 \%)$ & 1 & \\
\hline \multicolumn{5}{|l|}{ Level of education } \\
\hline Degree & $86(76.8 \%)$ & $26(23.2 \%)$ & $4.23(0.53-3.73)$ & $8.0(0.45-4.27)$ \\
\hline Diploma & $46(64.8 \%)$ & $25(35.2 \%)$ & $7.61(0.95-6.30)^{*}$ & $3.8(2.20-6.20)^{*}$ \\
\hline M.Sc. and above & $14(93.3 \%)$ & $1(6.7 \%)$ & 1 & 1 \\
\hline \multicolumn{5}{|l|}{ Working experience } \\
\hline Less than 2 years & $44(88.0 \%)$ & $6(12.0 \%)$ & $0.32(0.12-0.82)$ & $1.2(0.30-5.30)$ \\
\hline $2-5$ years & $35(67.3 \%)$ & $17(32.7 \%)$ & $1.12(0.54-2.32)$ & $3.2(0.93-11.14)$ \\
\hline 5 years and above & $67(69.8 \%)$ & $29(30.2 \%)$ & 1 & \\
\hline \multicolumn{5}{|c|}{ Received training on BEmONC } \\
\hline Yes & $89(68.5 \%)$ & $41(31.5 \%)$ & $2.4(1.13-5.02)^{*}$ & $5.6(1.10-28.50)^{*}$ \\
\hline No & $57(83.8 \%)$ & $11(16.2 \%)$ & 1 & 1 \\
\hline
\end{tabular}

* p-value $<0.05$

To have a complete picture of the situation, involve private health care providers and increasing the sample size and employing other methods may furnish better results and complement our findings.

\section{Limitation of the study}

Relatively small sample size which may affect estimate of a parameter and power of the test. Inclusion of private health care providers would have given comprehensive picture and make generalization possible. However, findings from this study can be regarded as a snapshot of current knowledge and practice of partograph utilization within the study area.

\section{Additional file}

Additional file 1: Table S1. Level of Knowledge of Partograph among obstetric care givers at public health institutions in central zone, Tigray, Ethiopia/2017. Table S2. Attitude of the participant towards the use of partograph among obstetric care givers at public health institutions in central zone, Tigray, Ethiopia/2017.

\section{Abbreviations}

Cl: confidence interval; AOR: adjusted odd ratio; SPSS: Statistical Package for Social Sciences; EDHS: Ethiopian Demographic and Health Survey; M. Sc.: Master of Science; BSc: Bachelor of Science; TRHB: Tigray Regional Health Bureau; MMR: maternal mortality rate; $\mathrm{BEmONC}$ : basic emergency obstetrics and newborn care.

\section{Authors' contributions}

TH conceived and designed the study, analyzed the data and wrote the manuscript. GG and BH data analysis, drafting of the manuscript and advising the whole research paper YM and KN were involved in the interpretation of the data and contributed to manuscript preparation. All authors read and approved the final manuscript.

\section{Authors' information}

TH holds M.Sc. in Maternity and Reproductive Health Nursing. TH has more than 9 years' experience in Midwifery Teaching and health research. TH is currently serving as the Lecturer at College of Health Sciences and Referral Hospital, Axum University, Ethiopia. BH, YM and KN hold master in Clinical Midwifery with more than 8 years' experience in Midwifery Teaching and research. GG holds M.Sc. in Maternity and Reproductive Health Nursing. GG has 10 years' experience in Midwifery Teaching and health research.

\section{Acknowledgements}

We would like to thank all study participants and data collectors for their contribution in success of our work. 


\section{Competing interests}

The authors declare that they have no competing interests.

\section{Availability of data and materials}

The data sets used and analyzed during the current study available from the corresponding author on reasonable request.

\section{Consent to publish}

Not applicable.

\section{Ethics approval and consent to participate}

Ethical clearance was secured from the Aksum University, College of Health Science research review committee. An official letter of permission was obtained from Tigray Regional Health Bureau. Respondents were well informed about the purpose of the study, and information was collected after full oral and written consent from participants. Information was recorded anonymously and confidentially, and beneficence was assured throughout the study period.

\section{Funding}

There is no funding for this research. All cost of data collection and analysis were covered by the authors.

\section{Publisher's Note}

Springer Nature remains neutral with regard to jurisdictional claims in published maps and institutional affiliations.

Received: 13 August 2018 Accepted: 3 October 2018

Published online: 10 October 2018

\section{References}

1. WHO. Maternal health and safe mother hood program. Geneva: WHO; 1994

2. Philpot $\mathrm{RH}$, Castele W. Cervicographs in the management of labor in primigravidas, action line \& treatment of abnormal labor. J Obstet Gynecol Br Commonwealth. 1972;79:599-602.

3. Opoku BK, Nguah SB. Utilization of the modified WHO partograph in assessing the progress of labour in a metropolitan area in Ghana. Res J Women's Health. 2015;2(1):2.

4. World Health Organization. Reduction of maternal mortality. Geneva: A joint WHO/UNFPA/UNICEF/World Bank statement; 1999.

5. Dangal G. Preventing prolonged labor by using partograph. Internet J Gynecol Obstet. 2006;7(1).
6. WHO, UNFPA, World Bank Group and the United Nations Population Division. Trends in maternal mortality: 1990 to 2015 estimates by WHO, UNICEF, 2015, UNFPA. Geneva: World Bank Group and the United Nations Population Division; 2015.

7. Central Statistical Agency. Ethiopian demographic health survey. Ethiopia: Central Statistical Agency; 2016. p. 249

8. Yisma E, Dessalegn B, Astatike A, Fissha N. Knowledge and utilization of partograph among obstetric care givers in public health institution of Addis Ababa, Ethiopia. BMC Pregnancy Childbirth. 2013;13:1-9.

9. Wakgari N, Amano A, Berta M, Tessema GA. Partograph utilization and associated factors among obstetric care providers in North Shoa Zone, Central Ethiopia. Afr Health Sci. 2015;15:551-9.

10. Fawole A, Hunyinbo K, Adekanle D. Knowledge and Utilization of the partograph among obstetric care givers in South West Nigeria. Afr J Reprod Health. 2008;12(1):22-9

11. Zelellw DA, Tegegne TK. Level of partograph utilization and its associated factors among obstetric caregivers at public health facilities in East Gojam Zone, Northwest Ethiopia. PLoS ONE. 2018;13(7):e0200479.

12. Opiah MM, Ofi AB, Essien EJ, Monjok E. Knowledge and utilization of the partograph among midwives in the Niger delta region of Nigeria. Afr J Reprod Health. 2012;16:1-8.

13. Agan TU, Akpan U, Okokon IB, Oku AO, Asibong UE. Assessment of the knowledge and utilization of the partograph among non-physician obstetric care givers in the University of Calabar Teaching Hospital, Calabar, Nigeria. Br J Med Med Res. 2014:4(36):5741-55.

14. Fawole AO, Hunyinbo K, Adekanle DA. Knowledge and utilization of the partograph among obstetric care givers in South West Nigeria. Afr J Reprod Health. 2008;12:1-8

15. Bekele D, Beyene K, Hinkosa L, Shemsu MN. Partograph utilization and associated factors among graduating health professional students in Asella Referral and Teaching Hospital, Ethiopia. J Comput Biol. 2016:6:1-7.

16. Eshetu K, Hussen E, Dulla D. Magnitude of partograph use and associated factors among obstetric care givers in public health institution in Sidama Zone, southern Ethiopia. Divers Equality Health Care. 2017;14(6):316-23.

17. Zelelew DA, Tegegne TK. Level of partograph utilization and its associated factors among obstetric care givers at public health facilities in East Gojam. PLoS ONE. 2016;13(7):1-13.

Ready to submit your research? Choose BMC and benefit from

- fast, convenient online submission

- thorough peer review by experienced researchers in your field

- rapid publication on acceptance

- support for research data, including large and complex data types

- gold Open Access which fosters wider collaboration and increased citations

- maximum visibility for your research: over 100M website views per year

At $\mathrm{BMC}$, research is always in progress.

Learn more biomedcentral.com/submissions 